\title{
Spatial Pattern in Aerosol Insecticide Deposition Inside a Flour Mill
}

\author{
JAMES F. CAMPBELL, ${ }^{1,2}$ FRANK H. ARTHUR, ${ }^{1}$ AND KUN YAN ZHU ${ }^{3}$
}

\begin{abstract}
J. Econ. Entomol. 107(1): 440-454 (2014); DOI: http://dx.doi.org/10.1603/EC13423
ABSTRACT Aerosol insecticides are commonly used for management of stored-product pests inside food facilities, but the physical complexity of the interior of most food facilities may influence the dispersal and deposition of droplets and create spatial variation in dosage. The spatial pattern in aerosol deposition was evaluated inside a flour mill using a high density grid of bioassay insects. Three insecticides, Aerotech with NyGuard and Pyrocide $100+$ Diacon II, both pyrethrin and insect growth regulator combinations, and Vap20, an organophosphate, were evaluated at normal $\left(27^{\circ} \mathrm{C}\right)$ and high $\left(40^{\circ} \mathrm{C}\right)$ target temperatures. Using a newly developed efficacy index, there was spatial pattern to aerosol deposition detected for the pyrethrin insecticides and the pattern differed between aerosols and temperatures. Walls and corners, especially behind the direction of application, were especially vulnerable to zones of lower efficacy, and open areas in center of the room tended to have the highest efficacy. The organophosphate insecticide provided complete efficacy at all bioassay dish locations, probably due in part to its vapor toxicity. Using boxes $1 \mathrm{~m}$ in depth and 5,10 , or $20 \mathrm{~cm}$ in height and open on only one end, it was shown that aerosol dispersal under horizontal surfaces could be impacted by gap height, aerosol, and temperature. These results show the potential for spatial variation in aerosol efficacy within a food facility and identify locations with the potential to receive a lower insecticide dosage. To increase overall efficacy, these locations may be targeted for additional interventions to provide more uniform pest population suppression.
\end{abstract}

KEY WORDS confused flour beetle, flour mill, aerosol, spatial pattern, dispersion

Aerosol insecticides can be used as part of an integrated pest management program for food facilities such as mills, food-processing plants, warehouses, and distribution centers. An aerosol treatment, also called space, ultra-low volume, or fogging treatment, involves the release of insecticide into the air in the form of small droplets (5-50 $\mu \mathrm{m}$ in diameter). There is a long history of aerosol use in food facilities, but applications have been increasing in recent years due in part to the decreasing amount of structural fumigation (Peckman and Arthur 2005, Arthur 2012, Boina and Subramanyam 2012). Typically, aerosols have limited penetration ability and limited residual activity on surfaces and therefore are primarily targeting flying, roosting, or walking insects in open areas at the time of the application. However, inside food facilities, some aerosol insecticides can settle on surfaces and offer residual control (Sutton et al. 2011).

Aerosol applications can provide more complete coverage of surfaces within a structurally complex

\footnotetext{
Mention of trade names or commercial products in this publication is solely for the purpose of providing specific information and does not imply recommendation or endorsement by the U.S. Department of Agriculture or by Kansas State University. USDA is an equal opportunity provider and employer.

${ }^{1}$ USDA, Agricultural Research Service, Center for Grain and Animal Health Research, 1515 College Ave., Manhattan, KS 66502.

${ }^{2}$ Corresponding author, e-mail: james.campbell@ars.usda.gov.

${ }^{3}$ Department of Entomology, Kansas State University, Manhattan, KS 66506.
}

food facility than is feasible with conventional spray applications. This improved coverage increases the chance of a stored-product insect encountering the insecticide either during application or afterwards through contact with a treated surface. However, because at a given point in time most of the pest population is located in hidden areas (e.g., inside equipment, accumulated food in cracks and crevices, under pallets, inside packaged food), only a small percentage of individuals are likely to be directly exposed during an aerosol application (Toews et al. 2010, Arthur et al. 2013). The structural complexity of many food facility interiors may also influence the dispersal and deposition of aerosol droplets, creating spatial variation in dosage.

Commonly used aerosols in the food industry are the organophosphate dichlorvos (DDVP), synergized pyrethrins, pyrethroids, and insect growth regulators (IGRs; Boina and Subramanyam 2012). Often IGRs such as methoprene, hydroprene, or pyriproxyfen are applied in combination with pyrethrins or pyrethroids. Aerosol insecticides are typically applied using a handheld or portable aerosol applicator with an atomizing nozzle, a pressurized cylinder using a carrier gas such as $\mathrm{CO}_{2}$, or a permanently installed pressurized overhead system. Each application method can produce a different range of droplet sizes and a different pattern of aerosol dispersal and deposition. There have been a number of recent studies on effi- 
cacy of these applications, which are discussed below, but there are comparatively less data regarding the spread and dispersal of aerosols within food facilities.

Insecticides applied as aerosols have been demonstrated to be effective against stored-product insects using a variety of methods. The majority of the research on efficacy has been under laboratory conditions simulating aerosol applications made directly to the insects (Harein et al. 1971; Arthur 1988, 1993; Arthur and Gillenwater 1990; Tucker et al. 2014) or aerosol applications conducted in small rooms (Jenson et al. 2010a, Toews et al. 2010, Kharel et al. 2013). Data on the efficacy of aerosol insecticides applied at the scale and under the conditions typically found in commercial applications are much more limited. One approach used to measure efficacy of commercial scale applications, where it is typically not possible to introduce live insects for bioassays, has been to expose bioassay dishes to the aerosol, and afterwards add insects to the treated surfaces (Arthur 2010, Sutton et al. 2011). Given that some aerosol insecticides have limited residual activity (e.g., dichlorvos, pyrethrins), there are constraints where this can be applied. Another approach that can typically only be used in nonoperational or research facilities is to place dishes with insects out during an aerosol application and evaluate the mortality afterward (Arthur 2008, Arthur and Campbell 2008, Jenson et al. 2010b, Subramanyam et al. 2014).

Temperatures at time of aerosol application can vary widely depending on the location and the time of year the application is made. Temperature can have an impact on insecticide efficacy. Pyrethrins and most pyrethroids have a negative temperature coefficient, while for most organophosphates toxicity increases with temperature (Schleier and Peterson 2011). Volatilization of the organophosphate insecticide dichlorvos increases with temperature, which can increase immediate efficacy of impregnated strips (Lehnert et al. 2011), but reduce residual activity on surfaces (Strong and Sbur 1964). However, little is known about how temperature within a food facility might impact insecticide droplet dispersal and the efficacy of aerosol insecticide applications.

Obtaining uniform coverage with an aerosol insecticide is critical to optimizing the effectiveness of the treatment within a food facility, but horizontal structural features (e.g., equipment, pallets, beams) within a structure may block the settling of aerosol droplets. Accumulations of food residue and hidden areas in equipment, wall voids, and cracks and crevices can create areas that are inaccessible to aerosol droplet penetration. Vertical structural features may interfere with the dispersal of the aerosol droplets after release. Studies done in relatively open rooms show generally good dispersion of aerosols (Arthur 2008, Arthur and Campbell 2008, Subramanyam et al. 2014), but efficacy was evaluated in only a limited number of locations.

The following experiment was conducted to evaluate spatial pattern in aerosol insecticide deposition within a food facility. A research flour mill was used so that bioassay insects could be introduced and a large array of bioassay dishes was placed within the mill so that a more accurate picture of the spatial pattern in efficacy could be assessed. The specific objectives were to: 1) determine the spatial pattern of efficacy of three different aerosol insecticides at two different temperatures (normal room temperature and high temperature) and 2) measure ability of these different insecticides, under the two temperature conditions, to disperse under horizontal obstructions of different heights. These bioassay dishes were used to evaluate spatial pattern in deposition, not to fully evaluate the impact of each aerosol insecticide. Ultimately, we wished to be able to predict zones within a facility that may not be obtaining adequate efficacy so that modifications to application methods or alternative supplemental treatments could be applied to generate a more uniform coverage.

\section{Materials and Methods}

Research Location. The experiments were conducted at the pilot-scale Hall Ross flour mill at Kansas State University in Manhattan, KS. The mill is a concrete structure composed of five floors. Four of the floors were used in this study. The top three floors received aerosol treatments: third floor with a volume of $1,504 \mathrm{~m}^{3}$, fourth floor $1,504 \mathrm{~m}^{3}$, and fifth floor 1,674 $\mathrm{m}^{3}$. The first floor served as the control floor. Separate aerosol applications were made to each floor, and gaps between the floors were sealed to isolate the floors from each other. Each floor was considered a separate replication. The second floor was not used and served as a buffer between the treatment floors and the control floor.

Treatments. The aerosol trials were conducted under normal (target $27^{\circ} \mathrm{C}$ ) and high temperature (target $40^{\circ} \mathrm{C}$ ) conditions. The normal temperature conditions trial was conducted on 23-25 January of 2012, and the high temperature conditions trial was conducted on 16-18 July of 2013. Temperature and relative humidity were monitored on each floor using a HOBO data logger (Onset Computers, Pocasset, MA) placed on the floor.

Three aerosol insecticides labeled for use in foodhandling facilities against stored-product insects were evaluated, and each was applied under both normal and high temperature conditions. All applications were performed by licensed applicators from Industrial Fumigant Company (Lenexa, KS). Aerotech with NyGuard (Chem-Tech, Des Moines, IA), hereafter termed Aerotech, contains $0.7 \%$ active ingredient [(AI)] pyrethrins, $5.0 \%$ piperonyl butoxide (synergist), and $0.2 \%$ of the IGR pyriproxyfen. It is formulated in a pressurized gas cylinder with $\mathrm{CO}_{2}$ as a carrier. Pyrocide 100 (MGK, Minneapolis, MN) and Diacon II (Wellmark, Schaumburg, IL) were mixed and applied together using a model 7401 Microjet Fogger (Fogmaster, Deerfield Beach, FL) set at the maximum flow rate. Pyrocide 100 contains $1.0 \%$ of the (AI) pyrethrins, $2.0 \%$ piperonyl butoxide (synergist), and $3.0 \% \mathrm{~N}-$ Octyl bicycloheptene dicarboximide (synergist). Diacon II contains $33.6 \%$ of the (AI) IGR 
Table 1. Aerosol treatment information and environmental conditions during treatment (mean \pm SEM of readings taken every 15 $\min )$

\begin{tabular}{|c|c|c|c|c|c|c|}
\hline Temperature & Start date and time & Treatment & Floor & Aerosol applied ${ }^{a}$ & $\begin{array}{l}\text { Air temp } \\
\quad\left({ }^{\circ} \mathrm{C}\right)\end{array}$ & $\mathrm{RH}(\%)$ \\
\hline \multirow[t]{12}{*}{ Normal $27^{\circ} \mathrm{C}$ target } & \multirow[t]{4}{*}{23 January $2012,11: 30$ am } & Aerotech with NyGuard & Fifth & $538 \mathrm{mg} / \mathrm{m}^{3}$ & $23.2 \pm 0.0$ & $15.0 \pm 0.0$ \\
\hline & & Aerotech with NyGuard & Fourth & $592 \mathrm{mg} / \mathrm{m}^{3}$ & $25.7 \pm 0.1$ & $15.0 \pm 0.0$ \\
\hline & & Aerotech with NyGuard & Third & $599 \mathrm{mg} / \mathrm{m}^{3}$ & $27.0 \pm 0.1$ & $15.0 \pm 0.0$ \\
\hline & & Control & First & na & $24.7 \pm 0.1$ & $15.0 \pm 0.0$ \\
\hline & \multirow[t]{4}{*}{24 January $2012,10: 45$ am } & Pyrocide $100+$ Diacon II & Fifth & 0.521 and $0.011 \mathrm{ml} / \mathrm{m}^{3}$ & $25.1 \pm 0.0$ & $15.0 \pm 0.0$ \\
\hline & & Pyrocide $100+$ Diacon II & Fourth & 0.521 and $0.011 \mathrm{ml} / \mathrm{m}^{3}$ & $27.7 \pm 0.1$ & $15.0 \pm 0.0$ \\
\hline & & Pyrocide $100+$ Diacon II & Third & 0.521 and $0.011 \mathrm{ml} / \mathrm{m}^{3}$ & $28.7 \pm 0.1$ & $15.0 \pm 0.0$ \\
\hline & & Control & First & na & $23.5 \pm 0.0$ & $15.0 \pm 0.0$ \\
\hline & \multirow[t]{4}{*}{24 January $2012,10: 45$ pm } & Vap20 & Fifth & $398 \mathrm{mg} / \mathrm{m}^{3}$ & $24.5 \pm 0.0$ & $15.0 \pm 0.0$ \\
\hline & & Vap20 & Fourth & $359 \mathrm{mg} / \mathrm{m}^{3}$ & $26.3 \pm 0.0$ & $15.0 \pm 0.0$ \\
\hline & & Vap20 & Third & $354 \mathrm{mg} / \mathrm{m}^{3}$ & $27.3 \pm 0.0$ & $15.0 \pm 0.0$ \\
\hline & & Control & First & na & $22.7 \pm 0.0$ & $15.0 \pm 0.0$ \\
\hline \multirow[t]{12}{*}{ High $40^{\circ} \mathrm{C}$ target } & \multirow[t]{4}{*}{16 July $2012,10: 00 \mathrm{am}$} & Aerotech with NyGuard & Fifth & $590 \mathrm{mg} / \mathrm{m}^{3}$ & $42.8 \pm 0.0$ & $28.1 \pm 0.3$ \\
\hline & & Aerotech with NyGuard & Fourth & $593 \mathrm{mg} / \mathrm{m}^{3}$ & $43.2 \pm 0.0$ & $27.8 \pm 0.1$ \\
\hline & & Aerotech with NyGuard & Third & $603 \mathrm{mg} / \mathrm{m}^{3}$ & $37.5 \pm 0.1$ & $32.7 \pm 0.4$ \\
\hline & & Control & First & na & $41.2 \pm 0.0$ & $30.9 \pm 0.2$ \\
\hline & \multirow[t]{4}{*}{17 July $2012,9: 00 \mathrm{am}$} & Pyrocide $100+$ Diacon II & Fifth & 0.521 and $0.011 \mathrm{ml} / \mathrm{m}^{3}$ & $41.4 \pm 0.0$ & $28.6 \pm 0.0$ \\
\hline & & Pyrocide $100+$ Diacon II & Fourth & 0.521 and $0.011 \mathrm{ml} / \mathrm{m}^{3}$ & $40.5 \pm 0.0$ & $29.9 \pm 0.0$ \\
\hline & & Pyrocide $100+$ Diacon II & Third & 0.521 and $0.011 \mathrm{ml} / \mathrm{m}^{3}$ & $36.2 \pm 0.0$ & $32.0 \pm 0.5$ \\
\hline & & Control & First & na & $40.9 \pm 0.0$ & $29.4 \pm 0.3$ \\
\hline & \multirow[t]{4}{*}{17 July $2012,10: 00$ pm } & Vap20 & Fifth & $352 \mathrm{mg} / \mathrm{m}^{3}$ & $41.5 \pm 0.0$ & $23.1 \pm 0.2$ \\
\hline & & Vap20 & Fourth & $347 \mathrm{mg} / \mathrm{m}^{3}$ & $41.2 \pm 0.1$ & $22.4 \pm 0.4$ \\
\hline & & Vap20 & Third & $362 \mathrm{mg} / \mathrm{m}^{3}$ & $36.4 \pm 0.0$ & $30.0 \pm 0.1$ \\
\hline & & Control & First & na & $41.1 \pm 0.0$ & $24.6 \pm 0.1$ \\
\hline
\end{tabular}

na, not applicable.

${ }^{a}$ For Pyrocide $100+$ Diacon II aerosol treatments the first amount is for Pyrocide 100 and second amount is for the Diacon II

(S)-methoprene. This mixture is hereafter termed Pyrocide. The third aerosol insecticide applied was Vap20 (Chem-Tech), which contains $18.6 \%$ of the organophosphate (AI) dichlorvos. This formulation is in a pressurized gas cylinder with $\mathrm{CO}_{2}$ as a carrier. The amount of insecticide applied was based on the label rate, with the specific amounts applied during each application reported in Table 1. For those treatments applied based on weight, the actual amount of insecticide applied was close to the target amount in all treatments.

Application of the aerosols was from a single location $\approx 3-4$ m out toward the middle of the room from the double doors to the elevator lobby (Fig. 1). Applications using pressurized cylinders were made using short bursts with the nozzle facing to the right, straight, and to the left. With the handheld applicator, applications were made another $1.5 \mathrm{~m}$ further into the room because release velocity is less than the cylinderized insecticides and applied at a 45 degree angle in an arc from right to left. After releasing the required amount of insecticide, there was an 8-h exposure period with the air handling system turned off (i.e., relatively still air conditions) before the mill was aerated (aeration times were variable, typically $\approx 30 \mathrm{~min}$ for Aerotech and Pyrocide and $\approx 4 \mathrm{~h}$ for Vap20, and were based on applicator assessment of safety). Each aerosol insecticide formulation was applied to each of the three treatment floors sequentially on a given treatment day (Table 1).

Spatial Distribution of Deposition. Before each aerosol application, a grid of 75 petri dishes $(35 \mathrm{~mm}$ in diameter) containing five adult Tribolium confusum Jacquelin du Val (laboratory strain) and $0.25 \mathrm{~g}$ of flour was placed on each of the treated floors. Adults added were mixed sex and $<4$ wk of age. Beetles were added to the dishes with flour $<48 \mathrm{~h}$ before placement in the mill. The distribution of dishes was similar on each floor of the mill, but differences did occur owing to variation in the layout of equipment and other structural features among floors. Locations where dishes were placed were classified as open (not underneath an obstruction to settling aerosol droplets and not adjacent to a vertical edge such as a wall or pillar), adjacent (not underneath an obstruction, but close $[<6 \mathrm{~cm}]$ to a vertical edge), and covered (underneath an obstruction).

Dishes were placed out on each floor $1-2 \mathrm{~h}$ before start of the aerosol application, and the lids were removed and placed under the dish. Using uncovered dishes was important because using cages to confine insects can reduce the amount of aerosol to which the insect is exposed (Hoffmann et al. 2008). Because T. confusum does not fly and cannot climb out of the open dishes, beetles could be confined to the dishes under both sets of temperatures tested. The dishes were covered $1-2 \mathrm{~h}$ after the completion of aeration process and returned to the laboratory. The control first floor had 25 dishes divided into two groups placed at opposite ends of the floor. An additional set of 25 control dishes were held continuously under laboratory conditions and were used to determine effects of transporting and holding the dishes under conditions within the mill. After $24 \mathrm{~h}, 1$ and $2 \mathrm{wk}$ posttreatment, the five beetles within a dish were classified as active (walking normally), affected (exhibiting symptoms of knockdown ranging from completely inactive and only responding to touch with a probe to walking for 
$3^{\text {rd }}$ Floor

A. Normal Temperature
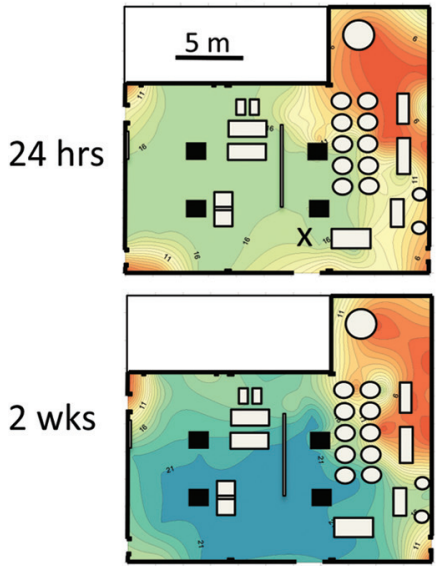

2 wks

. High Temperature
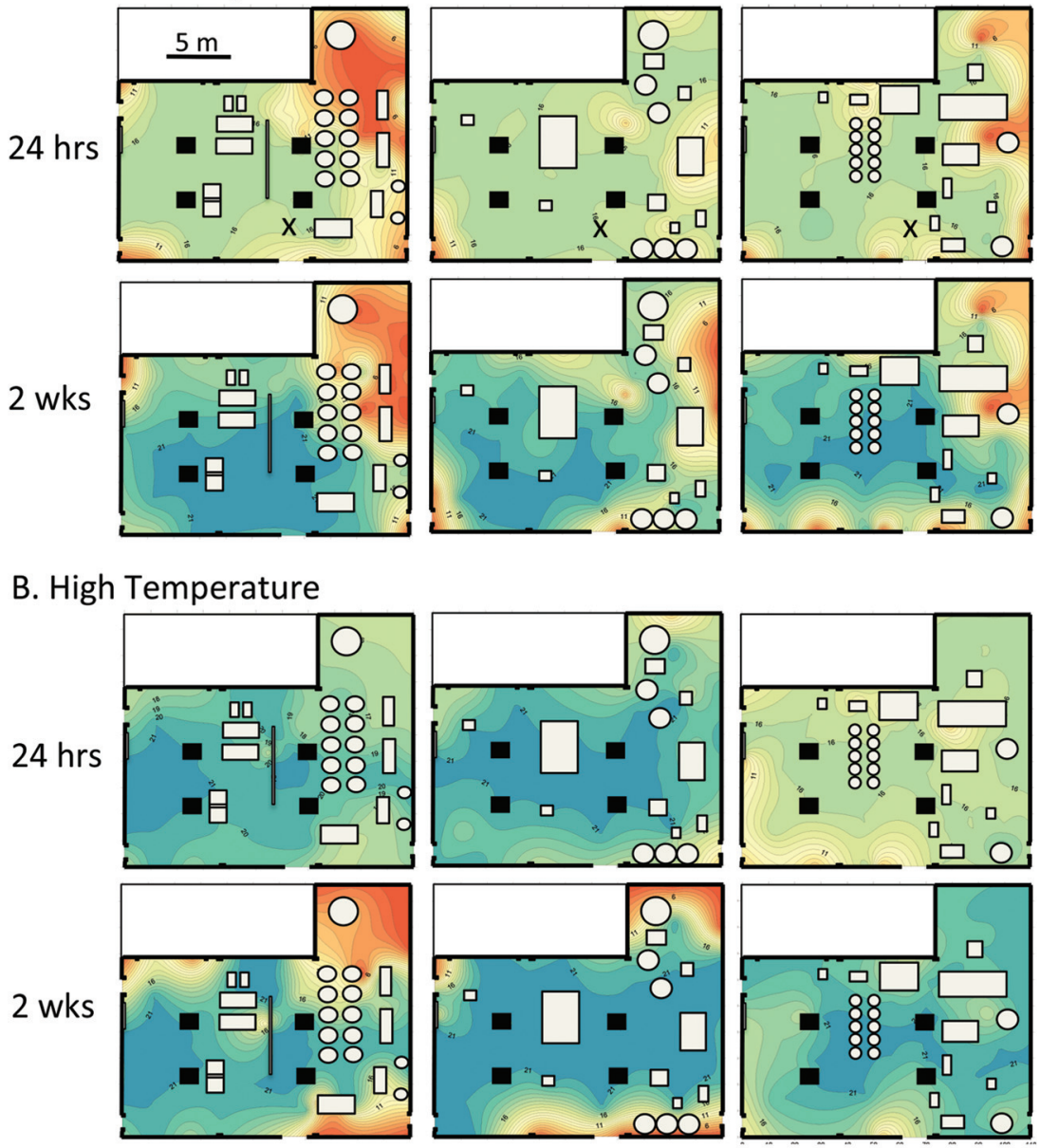

Efficacy Index $5^{\text {th }}$ Floor 
$(4,0,1), 4(3,2,0), 5(3,1,1), 6(3,0,2), 7(2,3,0), 8(2,2,1)$, $9(2,1,2), 10(2,0,3), 11(1,4,0), 12(1,3,1), 13(1,2,2), 14$ $(1,1,3), 15(1,0,4), 16(0,5,0), 17(0,4,1), 18(0,3,2), 19$ $(0,2,3), 20(0,1,4), 21(0,0,5)$.

To visualize the spatial pattern of aerosol deposition on each floor, contour maps of the index values at each dish location were developed based on Kriging using Surfer software (Golden Software, Golden, CO). Separate maps were made for each floor, each treatment, and each time posttreatment. The area of each contour map with high efficacy and low efficacy was also calculated. Areas of high efficacy were defined as those with all five beetles exhibiting a response to the treatment, either affected or dead, and this corresponded to the area of the map with an efficacy index value $\geq 16$. Areas with low efficacy were those where all five beetles were without visible treatment effects, $\leq 1$ efficacy index. These areas were calculated by creating separate contour maps that only mapped areas above or below these thresholds and using Image J software (Schneider et al. 2012), to trace the combined areas in each map and calculate the percentage of the total area on each floor that was represented by each level of efficacy. Differences in area between temperatures and between the two pyrethrin treatments were compared using $t$-tests (SigmaPlot v. 12, Systat Software, San Jose, CA).

To further evaluate the levels of efficacy, the index values for the different insecticide formulation and temperature combinations, using individual bioassay dish locations from all three floors as replicates, were compared at each time postexposure using the Wilcoxon Signed Rank Test (SigmaPlot), as distributions were not normal. In addition, the mean index value for three types of dish locations-open, adjacent, and covered - was calculated and compared using analysis of variation (ANOVA) and the Ryan-Einot-GabrielWelsch multiple range test (SAS/STAT software v. 9.2, SAS Institute, Cary, NC) at each time posttreatment. Data in text and tables are presented as mean \pm SEM, and all statistical comparisons were made at $\alpha=$ 0.05 level.

Impact of Obstruction Gap Height on Aerosol Deposition. Boxes of different heights were used to determine how effectively the aerosol droplets dispersed under obstructions. Boxes were $1 \mathrm{~m}$ in length, $20 \mathrm{~cm}$ in width, and either 5,10 , or $20 \mathrm{~cm}$ in height and were open on only one end. The boxes were constructed from 1.6-cm-thick plywood and covered in plastic sheeting. Five petri dishes containing five adult $T$. confusum and $0.25 \mathrm{gm}$ of flour, created as described above, were placed on the floor at different distances under the box. Rows of five dishes were placed $8 \mathrm{~cm}$ in front of the open end of the box, and at 8, 36, 64, and $91 \mathrm{~cm}$ under the box. The dishes were placed $1 \mathrm{~cm}$ from the sides of the box, and $\approx 0.1 \mathrm{~cm}$ apart from each other. One box of each height was placed on each of the three treatment floors and on the control floor. Boxes were $\approx 12 \mathrm{~m}$ from the point of aerosol release and the open end of the box was facing away from the point of release. Dishes were collected and insect response assessed as described above. Data were an- alyzed using ANOVA and the Ryan-Einot-GabrielWelsch multiple range test (SAS/STAT software) at the $\alpha=0.05$ level.

\section{Results}

Good separation between the normal and high temperature treatments was obtained within the mill, but it was difficult to obtain consistent temperatures across the different floors or within a floor over time owing to structural differences between floors and also because the heating system was turned off during the trials (Table 1). During the normal temperature treatment $\left(27^{\circ} \mathrm{C}\right.$ target $)$, the average temperatures ranged between $4.3^{\circ} \mathrm{C}$ below and $1.7^{\circ} \mathrm{C}$ above the target. The bottom (first) and top (fifth) floors tended to be cooler, probably because of the cold outside conditions: outside daily average temperature was $1.9 \pm 0.5^{\circ} \mathrm{C}$, minimum and maximum temperatures were $-6.1^{\circ} \mathrm{C}$ and $11.1^{\circ} \mathrm{C}$, respectively. Relative humidity $(\mathrm{RH})$ was very low inside during the normal temperature trial, with an average of $15 \% \mathrm{RH}$ that was the lower limit of the data loggers. During the high temperature treatment $\left(40^{\circ} \mathrm{C}\right.$ target $)$, average temperatures during a treatment ranged from $3.8^{\circ} \mathrm{C}$ below to $3.2^{\circ} \mathrm{C}$ above the target. Floors were more consistent in temperature than at the normal temperature trials, although the third floor tended to be a little cooler than the others. Outside temperature during the experiment was $30.2 \pm 1.0^{\circ} \mathrm{C}$, and ranged from 22.2 to $40.6^{\circ} \mathrm{C}$. Relative humidity inside the mill ranged from 23 to $33 \%$.

Spatial Distribution of Aerosol Deposition Maps. The three aerosol formulations and application methods had different patterns of deposition. All T. confusum exposed to Vap 20 were dead $1 \mathrm{wk}$ after treatment regardless of exposure position or temperature; hence, contour mapping and analysis of spatial pattern were not performed. For the other two aerosols, there were differences in the spatial pattern of the efficacy and differences between insecticides, over time postexposure, and between temperatures could be evaluated.

For Aerotech applications, there were areas on each floor with both low and high efficacy index values, and the general pattern was similar among the floors (Fig. 1). Areas of lower efficacy tended to occur in the short arm portion of the L-shaped room (farthest away from point of release), but also along the walls, especially in corners and along the wall behind where the applicator stood. Areas of higher efficacy tended to be in open areas in the center of the room. The increase in area with low and high efficacy from $24 \mathrm{~h}$ to $2 \mathrm{wk}$ postexposure reflects change in T. confusum adult response over time after treatment, with individuals initially affected either recovering or having died. For the contour maps generated using efficacy index values at $24 \mathrm{~h}, 1 \mathrm{wk}$, and $2 \mathrm{wk}$ posttreatment, the percentage of each map with high and low efficacy was similar among the floors (Table 2). There was no obvious pattern in the contour maps indicating that physical features such as pillars or pieces of equipment 
Table 2. Percentage of efficacy index contour map for Aerotech (Aerotech with NyGuard) and Pyrocide (Pyrocide $100+$ Diacon II) at each temperature and floor treatment combination with high efficacy (treatment effects on all five beetles-either immobilized or dead) or low efficacy (all five beetles without visible effects of treatment)

\begin{tabular}{|c|c|c|c|c|c|}
\hline Treatment & Target temp & Floor & $\begin{array}{l}\text { Time after } \\
\text { treatment }\end{array}$ & $\begin{array}{l}\% \text { Area with } \\
\text { high efficacy }\end{array}$ & $\begin{array}{l}\% \text { Area with } \\
\text { low efficacy }\end{array}$ \\
\hline \multirow[t]{12}{*}{ Aerotech } & Normal $\left(27^{\circ} \mathrm{C}\right.$ target $)$ & Third & $24 \mathrm{~h}$ & 40.6 & 4.2 \\
\hline & & & $1 \mathrm{wk}$ & 48.7 & 1.2 \\
\hline & & & 2 wk & 69.1 & 1.0 \\
\hline & & Fourth & $24 \mathrm{~h}$ & 50.7 & 0.0 \\
\hline & & & $1 \mathrm{wk}$ & 42.6 & 1.6 \\
\hline & & & $2 w k$ & 70.8 & 0.1 \\
\hline & & Fifth & $24 \mathrm{~h}$ & 42.9 & 0.0 \\
\hline & & & $1 \mathrm{wk}$ & 41.0 & 0.4 \\
\hline & & & $2 w k$ & 65.5 & 0.0 \\
\hline & & Mean \pm SEM & $24 \mathrm{~h}$ & $44.7 \pm 3.1$ & $1.4 \pm 1.4$ \\
\hline & & & $1 \mathrm{wk}$ & $44.1 \pm 2.3$ & $1.1 \pm 0.3$ \\
\hline & & & $2 w k$ & $68.5 \pm 1.6$ & $0.4 \pm 0.3$ \\
\hline \multirow[t]{12}{*}{ Aerotech } & High $\left(40^{\circ} \mathrm{C}\right.$ target $)$ & Third & $24 \mathrm{~h}$ & 94.2 & 0.0 \\
\hline & & & 1 wk & 66.1 & 4.5 \\
\hline & & & $2 w k$ & 65.2 & 1.9 \\
\hline & & Fourth & $24 \mathrm{~h}$ & 93.3 & 0.0 \\
\hline & & & $1 \mathrm{wk}$ & 78.6 & 0.0 \\
\hline & & & $2 w k$ & 79.4 & 0.7 \\
\hline & & Fifth & $24 \mathrm{~h}$ & 97.6 & 0.0 \\
\hline & & & $1 \mathrm{wk}$ & 71.5 & 3.3 \\
\hline & & & 2 wk & 70.0 & 2.9 \\
\hline & & Mean \pm SEM & $24 \mathrm{~h}$ & $95.0 \pm 1.3$ & $0.0 \pm 0.0$ \\
\hline & & & $1 \mathrm{wk}$ & $72.1 \pm 3.6$ & $2.6 \pm 1.3$ \\
\hline & & & $2 w k$ & $71.5 \pm 4.2$ & $1.8 \pm 0.6$ \\
\hline \multirow[t]{12}{*}{ Pyrocide } & Normal $\left(27^{\circ} \mathrm{C}\right.$ target $)$ & Third & $24 \mathrm{~h}$ & 71.4 & 0.0 \\
\hline & & & 1 wk & 83.6 & 0.0 \\
\hline & & & $2 w k$ & 97.6 & 0.0 \\
\hline & & Fourth & $24 \mathrm{~h}$ & 37.9 & 0.0 \\
\hline & & & $1 \mathrm{wk}$ & 99.4 & 0.0 \\
\hline & & & $2 w k$ & 100.0 & 0.0 \\
\hline & & Fifth & $24 \mathrm{~h}$ & 42.3 & 0.0 \\
\hline & & & $1 \mathrm{wk}$ & 55.7 & 0.0 \\
\hline & & & $2 w k$ & 96.2 & 0.0 \\
\hline & & Mean \pm SEM & $24 \mathrm{~h}$ & $71.4 \pm 10.5$ & $0.0 \pm 0.0$ \\
\hline & & & $1 \mathrm{wk}$ & $79.6 \pm 12.8$ & $0.0 \pm 0.0$ \\
\hline & & & $2 w k$ & $97.9 \pm 1.1$ & $0.0 \pm 0.0$ \\
\hline \multirow[t]{12}{*}{ Pyrocide } & High $\left(40^{\circ} \mathrm{C}\right.$ target $)$ & Third & $24 \mathrm{~h}$ & 98.8 & 0.0 \\
\hline & & & $1 \mathrm{wk}$ & 72.8 & 0.0 \\
\hline & & & $2 w k$ & 63.1 & 0.0 \\
\hline & & Fourth & $24 \mathrm{~h}$ & 91.6 & 0.0 \\
\hline & & & $1 \mathrm{wk}$ & 94.9 & 0.0 \\
\hline & & & $2 w k$ & 85.8 & 0.0 \\
\hline & & Fifth & $24 \mathrm{~h}$ & 100.0 & 0.0 \\
\hline & & & $1 \mathrm{wk}$ & 86.4 & 0.0 \\
\hline & & & 2 wk & 79.0 & 0.0 \\
\hline & & Mean \pm SEM & $24 \mathrm{~h}$ & $96.8 \pm 2.6$ & $0.0 \pm 0.0$ \\
\hline & & & $1 \mathrm{wk}$ & $84.7 \pm 6.4$ & $0.0 \pm 0.0$ \\
\hline & & & $2 w k$ & $76.0 \pm 6.7$ & $0.0 \pm 0.0$ \\
\hline
\end{tabular}

in the interior of the room were impacting aerosol efficacy.

Comparing the normal and the high temperature treatments, the elevated temperature tended to increase the efficacy at 24 -h postexposure, but by 2 -wk postexposure, the efficacy under the two temperature treatments was similar. At the normal temperature, the area of high efficacy tended to increase over time and at the high temperature the area of low efficacy tended to increase over time. The percent area with high efficacy $24 \mathrm{~h}$ after treatment was significantly different between temperatures $(t=-15.13$; $\mathrm{df}=4$; $P<0.001$ ), averaging $45 \%$ at normal temperature and 95\% at high temperature. However, 2 wk after treatment, the area of high efficacy was 68 and $72 \%$ at the normal and high temperatures, respectively, and these areas were not different from each other $(t=-0.69$; $\mathrm{df}=4 ; P=0.264$; Table 2 ). There also appeared to be more variation in efficacy among the floors at the high temperature compared with the normal temperature treatment: percentage of 2 -wk postexposure efficacy contour maps with high efficacy varied by up to 14 percentage points among floors compared with the normal temperature treatment that varied by only five percentage points (Table 2).

For the Pyrocide aerosol, efficacy was more intermediate and uniform within a floor and varied less between floors (Fig. 2). There were no areas with low efficacy on all floors at both temperatures, but the areas of high efficacy appeared less extensive than with the Aerotech aerosol. Where zones of reduced efficacy occurred, they tended to be along 
$3^{\text {rd }}$ Floor

A. Normal Temperature
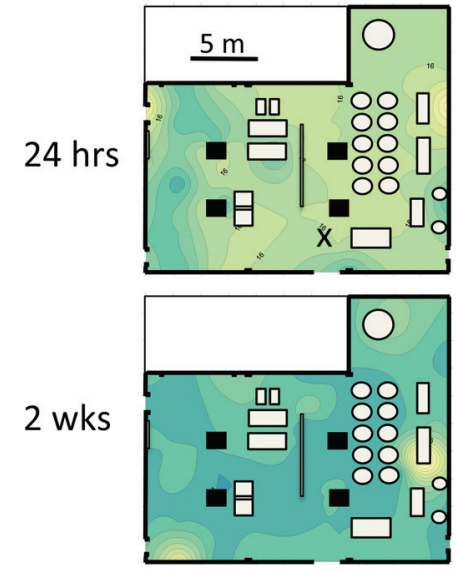

2 wks

B. High Temperature
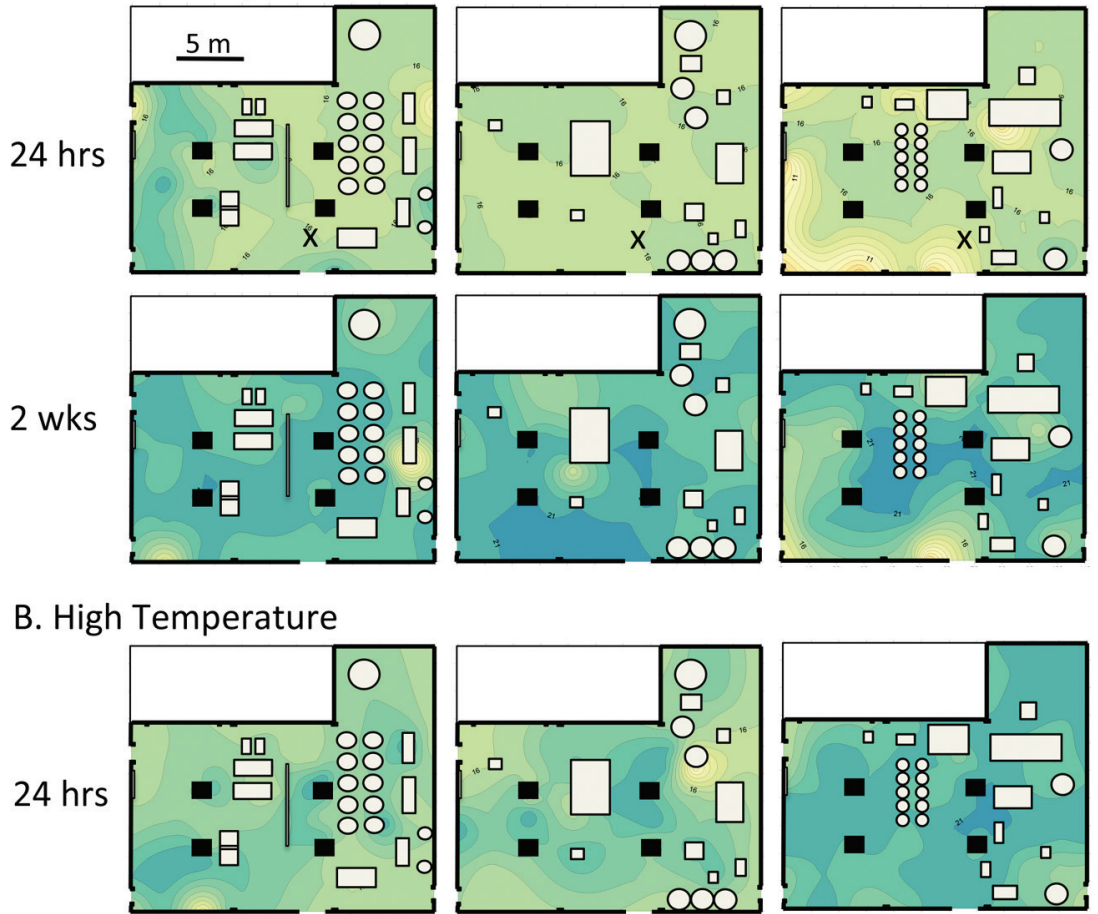

$5^{\text {th }}$ Floor

$4^{\text {th }}$ Floor
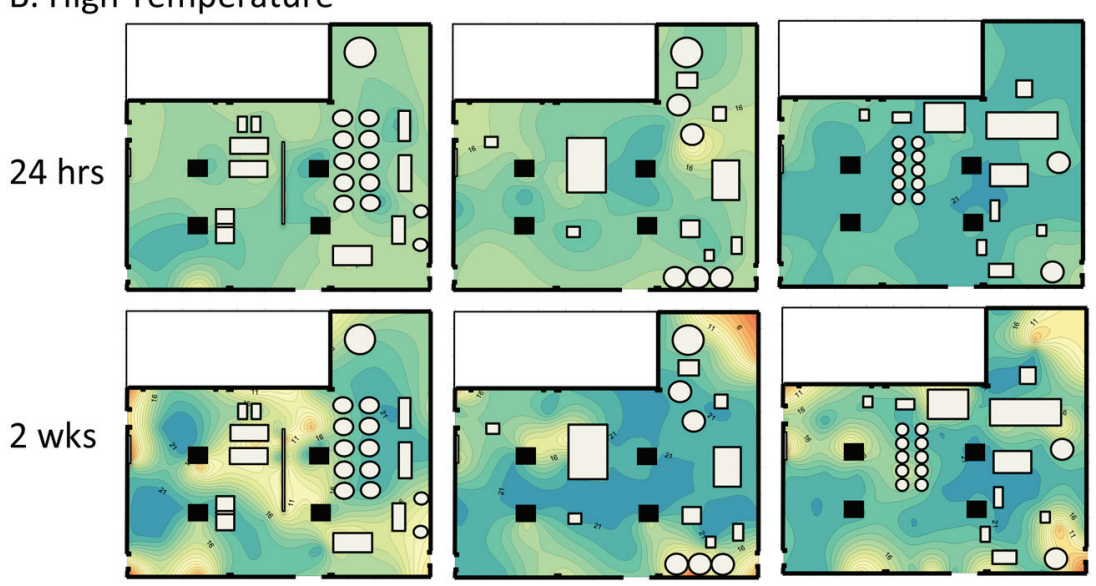

Efficacy Index

Low

High

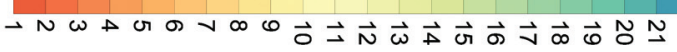

Fig. 2. Contour maps of the efficacy index values—range from lowest efficacy value of 1 up to highest efficacy value of 21 -for dishes ( $n=75$ per floor) containing five T. confusum exposed to Pyrocide aerosol applications at both (A) normal $\left(27^{\circ} \mathrm{C}\right)$ and $(\mathrm{B})$ high $\left(40^{\circ} \mathrm{C}\right)$ target temperatures at 24 -h and 2 -wk postexposure $(1 \mathrm{wk}$ data not shown) on each of the floors of a pilot scale flour mill. Gray shapes represent size and location of structural features such as milling equipment and storage bins and the black squares represent structural pillars. The $\mathrm{X}$ in the upper row of maps indicates the release location for the aerosol.

walls, in corners, and in the short arm of the Lshaped room, but in contrast to the Aerotech aerosol, these areas tended to be more apparent at the high temperature compared with the normal temperature treatment. After $2 \mathrm{wk}$, the percentage area with high efficacy was greater at the normal temperature $(98 \%)$ than at the high temperature $(76 \%$; $t=3.22 ; \mathrm{df}=4 ; P=0.032$; Table 2). This difference with temperature did not change over time and was also significant at $24 \mathrm{~h}(t=-46.27 ; \mathrm{df}=4 ; P=0.013$; Table 2), which also contrasted with results from the Aerotech aerosol.
Frequency Distribution of Efficacy Index Values. The frequency distribution of efficacy index values for all the dish locations across all three floors was different among the aerosol treatments, and initial efficacy increased with higher temperature during treatment (Fig. 3). For the Aerotech aerosol at normal temperature, immediately after treatment, most locations had an index value of 16 (all five beetles being affected), with remaining locations tending to have lower efficacy. Efficacy at a location typically increased over time postexposure and after $2 \mathrm{wk}$ most locations had an efficacy index of $\geq 16$, indicating that 


\section{Normal Temperature $\left(27^{\circ} \mathrm{C}\right.$ Target)}
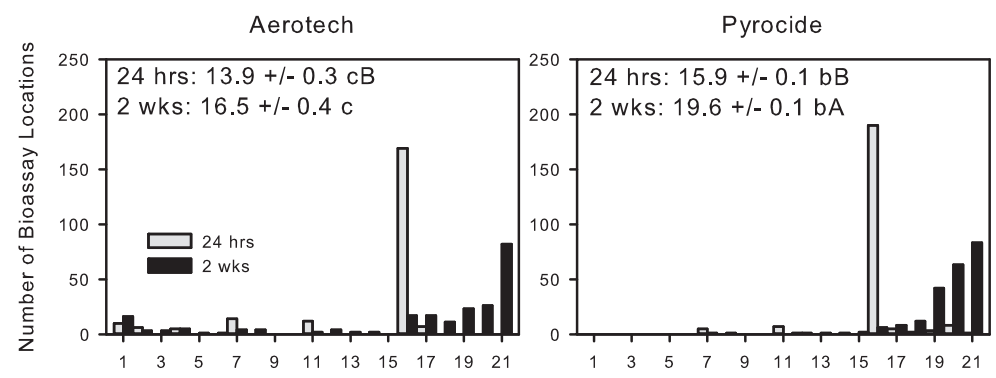

Vap20

High Temperature $\left(40^{\circ} \mathrm{C}\right.$ Target)
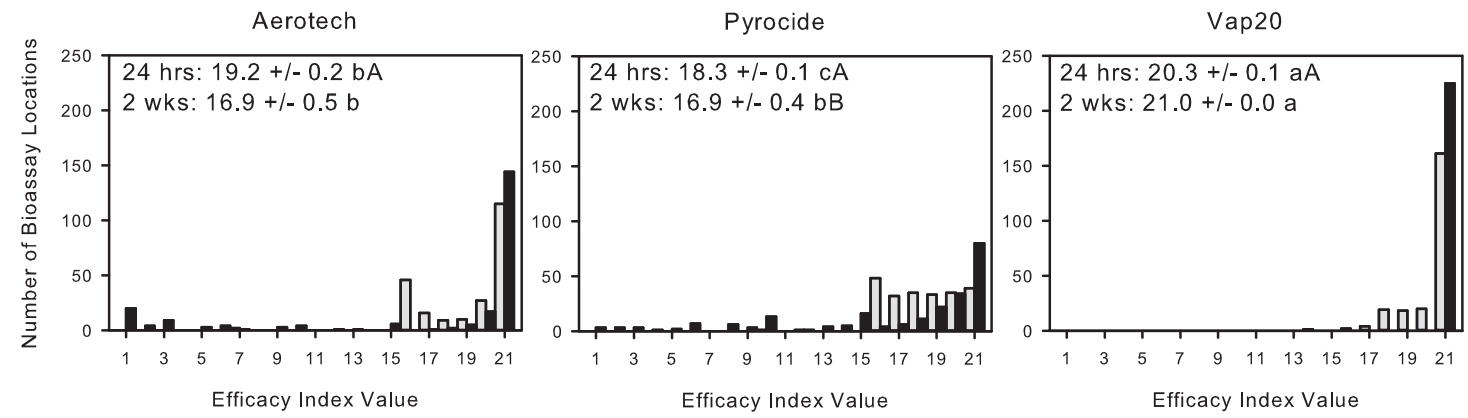

Fig. 3. Frequency distribution of the efficacy index values - range from lowest efficacy value of 1 up to highest efficacy value of 21 - among all the dish locations combined from the three floors of the mill $(n=225)$ for the three aerosols (Aerotech, Pyrocide, and Vap20) at both the normal and high temperatures. Gray bars indicate efficacy data at 24-h postexposure and the black bars efficacy after $2 \mathrm{wks}$ ( $1 \mathrm{wk}$ data not shown). Within each graph the mean \pm SEM is presented for each insecticide and temperature and time postexposure combination. Means followed by the same lower case letter are not different among insecticides within a temperature and time postexposure and means followed by the same upper case letters are not different between normal and high temperature within an insecticide and time postexposure (Wilcoxon Signed Rank Test).

most of the affected adults eventually died rather than recovered. In contrast, at the high temperature treatment, efficacy $24 \mathrm{~h}$ after treatment was more variable, with most locations having index values between 15 and 21. At 2-wk postexposure, most locations had the maximum efficacy index of 21 , but there was increased variation in efficacy, with index values ranging from 1 to 21 . The lower index values indicate some recovery by affected individuals. At 24 -h postexposure, the high temperature treatment had significantly greater efficacy (Wilcoxon Signed Rank Test, $Z=12.1 ; P<$ 0.001 ), but by 2 -wk postexposure, the two temperature treatments were not different from each other $(Z=1.7 ; P=0.097$; Fig. 3$)$.

As with the Aerotech aerosol, Pyrocide at the normal temperature had the same level of efficacy at most locations (index value of 16 , all individuals affected), although fewer locations had low efficacy (Fig. 3). After $2 \mathrm{wk}$, there was also a shift in efficacy, with more locations having a greater efficacy index, indicating that affected individuals failed to recover. The Pyrocide efficacy index was greater than the Aerotech efficacy index after both $24 \mathrm{~h}$ (Wilcoxon Signed Rank Test, $Z=5.6 ; P<0.001)$ and $2 \mathrm{wk}(Z=6.5 ; P<0.001)$. At the high temperature, there was more variation in efficacy index values 24-h postexposure than at the normal temperature, although most locations had values ranging between 16 and 21. After $2 \mathrm{wk}$, there was some recovery of affected individuals in many locations, and index values ranged between 1 and 21. At 24-h postexposure, the average efficacy index was greater at the high temperature than at the normal temperature $(Z=-10.1 ; P<0.001)$, but by 2 -wk postexposure, this had switched, and efficacy was greater at the normal temperature treatment than the high temperature treatment $(Z=5.8 ; P<0.001)$. This switch is owing to the increased recovery by affected adults after the high temperature treatment. At the high temperature, Aerotech had greater efficacy than Pyrocide at $24 \mathrm{~h}(\mathrm{Z}=-5.7 ; P<0.001)$, but the two treatments were not different from each other by 2 -wk postexposure $(Z=-0.8 ; P=0.416)$.

For the Vap20 treatment at both the normal and high temperature, there was some variation in efficacy index immediately after treatment, but only ranging between 13 ( 1 alive, 2 affected, and 2 dead) and 21 (all dead), and by 2 wk all locations had the maximum efficacy index of 21 (Fig. 3). At 24-h postexposure, efficacy was significantly greater at the higher temperature than the normal temperature $(Z=-5.2 ; P<$ $0.001)$. At 2 -wk postexposure, the two temperatures were not different from each other, as all the locations 
at both temperatures had the same value. At both the normal and high temperatures, Vap20 had a higher efficacy index than Aerotech at 24-h $(Z=12.8 ; P<$ 0.001 and $Z=5.9 ; P<0.001$, respectively) and 2 -wk $(Z=10.3 ; P<0.001$ and $Z=7.8 ; P<0.001$, respectively) postexposure. Furthermore, at both the normal and high temperatures, Vap20 had a higher efficacy index than Pyrocide at $24-\mathrm{h}(Z=12.2 ; P<0.001$ and $Z=10.7 ; P<0.001$, respectively $)$ and 2 -wk $(Z=10.4$; $P<0.001$ and $Z=10.4 ; P<0.001$, respectively) postexposure.

Bioassay Dish Position. The positions where bioassay dishes were placed, characterized as either covered, adjacent to a vertical surface, or in the open, had some influence on efficacy, which varied with insecticide and temperature (Fig. 4). The efficacy of Aerotech was most impacted by the position of the bioassay dish, with significant differences for all times postexposure at the high temperature, but only at 1-wk postexposure at the normal temperature. Generally, the dishes in open positions had the highest efficacy index, with covered and adjacent positions having lower efficacy, which was not significantly different from each other. Pyrocide only had significant differences among positions at 24-h postexposure at the normal temperature and at 2 -wk postexposure at the high temperature. As with the Aerotech aerosol, the open dishes had higher efficacy index values than the other two positions. The position effects seem to be greatest at the high temperature, with significantly greater efficacy after $2 \mathrm{wk}$ in the open position compared with covered or adjacent for both insecticides, while position was not significant after $2 \mathrm{wk}$ at the normal temperature. There was no significant position effect on Vap20 efficacy at either temperature.

Dispersion Under Horizontal Barriers. Use of the boxes of three different heights revealed differences in the ability of the different insecticides to disperse under horizontal barriers (Fig. 5). Generally, the results show that the shorter the gap height of the box the shorter the distance under the box that high efficacy could be maintained. There was also limited impact of temperature on this process, except with the Aerotech aerosol. As in the other analyses of distribution, Vap20 had high efficacy at all positions under the box, except for the 5-cm box where there was some survival at the furthest distances under the box though the trend was not significant.

With the 5-cm-tall box (Fig. 5), at the normal temperature, Aerotech aerosol had a significant decline in efficacy with distance under the box (ANOVA: $F=$ 41.0; $\mathrm{df}=4,10 ; P<0.001)$. Efficacy was reduced by $>50 \%$ just $8 \mathrm{~cm}$ inside the box and efficacy index values of $\approx 1$ (all beetles active) at nearly all positions further under the box. At the high temperature, there was better dispersal under the box and no significant difference in efficacy index among positions (ANOVA: $F=2.7 ; \mathrm{df}=4,10 ; P=0.0913$ ). The Pyrocide aerosol was less affected by temperature, and at both temperatures, there was a significant decrease in efficacy with distance under the box (normal temperature: $F=35.4$; $\mathrm{df}=4,10 ; P<0.001$, and high tem- perature: $F=64.7$;f $=4,10 ; P<0.001)$. As with the Aerotech aerosol at normal temperature, efficacy declined from the open position to the position that was $8 \mathrm{~cm}$ inside the box, and the efficacy index was usually 1 at all distances further under the box. There was no position effect with Vap20 aerosol at the normal (ANOVA: $F=1.6$; $\mathrm{df}=4,10 ; P=0.253$ ) or the high temperature (ANOVA: $F=3.0$; $\mathrm{df}=4,10 ; P=0.074$ ). However, there was some variation in efficacy at the two deepest positions, suggesting that an impact on efficacy was starting to occur.

With the 10-cm-tall box at the normal temperature (Fig. 5), the Aerotech aerosol had a significant decline in efficacy as the distance from the opening increased (ANOVA: $F=492.4$; $\mathrm{df}=4,10 ; P<0.001$ ). Unlike with the $5-\mathrm{cm}$ box, there was no difference in efficacy between the open position and the first position under the box, indicating better dispersal at this box height. However, the deeper positions under the box were similar to those at the 5-cm-height box, with most dishes having an index value of 1 (i.e., no detectable impact). At the high temperature, there was no significant decrease in efficacy index owing to a higher mean efficacy value and increased variation at the deeper positions within the box (ANOVA: $F=2.5$; df $=4,10 ; P=0.114)$. Thus at both temperatures, with a 10-cm gap, high efficacy could be obtained only up to the $8 \mathrm{~cm}$ distance underneath. For the Pyrocide aerosol, there was a significant decrease in efficacy with distance under the box at the normal (ANOVA: $F=42.5 ; \mathrm{df}=4,10 ; P<0.001)$ and high temperature (ANOVA: $F=57.2$; df $=4,10 ; P<0.001$ ). As with the 5 -cm box size, there was little apparent effect of temperature on dispersal under the box. High efficacy could be maintained up to $36 \mathrm{~cm}$ under the box, which was further than observed with the Aerotech aerosol. For the Vap20 aerosol, all positions under the box had the maximum efficacy values, so no detectable decline in efficacy occurred at this gap size.

With the 20-cm-tall box (Fig. 5), at the normal temperature, there was a significant decline in efficacy of the Aerotech aerosol with distance under the box (ANOVA: $F=357.5$; df $=4,10 ; P<0.001$ ). Up until the 36-cm-deep position, there was high efficacy, but deeper under the box, there was no detectable impact of the aerosol. However, at the high temperature, as with the other box heights, there was no significant decrease in efficacy index owing to distance under the box (ANOVA: $F=2.2$; $\mathrm{df}=4,10 ; P=0.145$ ). For the Pyrocide aerosol, there was a significant decrease in efficacy with distance under the box at the normal (ANOVA: $F=16.6$; $\mathrm{df}=4,10 ; P<0.001$ ) and high temperature (ANOVA: $F=15.8$; $\mathrm{df}=4,10 ; P<0.001$ ). Generally, with distance under the box the decrease at the normal temperature was less than observed with Aerotech aerosol. Furthermore, the average index value at the deeper positions under the box appeared greater at the high temperature compared with the normal temperature. For the Vap20 aerosol, the maximum efficacy values were obtained at all positions at both temperatures. 


\section{Normal Temperature $27^{\circ} \mathrm{C}$ Target}

High Temperature $40^{\circ} \mathrm{C}$ Target
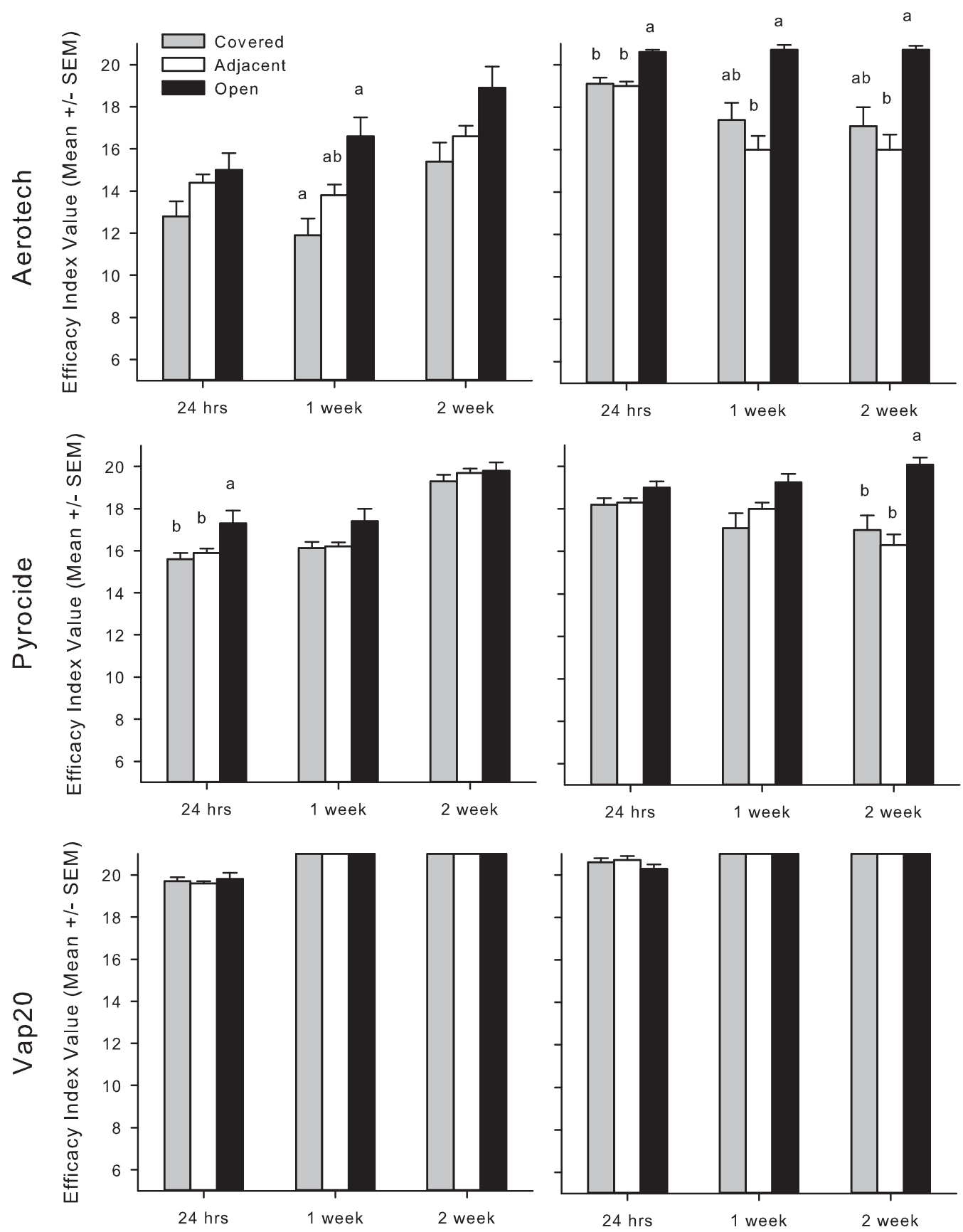

Time After Exposure to Aerosol

Fig. 4. Mean \pm SEM efficacy index value-range from lowest efficacy value of 1 up to highest efficacy value of $21-$ for dishes containing five T. confusum in covered locations, locations adjacent to vertical surfaces, and open locations for the three aerosol insecticides (Aerotech, Pyrocide, and Vap20) at both normal and high temperatures. Efficacy was evaluated at $24 \mathrm{~h}$, $1 \mathrm{wk}$, and $2 \mathrm{wk}$ postexposure and bars within a time postexposure with the same letter have means that are not significantly different among locations within an insecticide (ANOVA and the Ryan-Einot-Gabriel-Welsch multiple range test). 
Aerotech

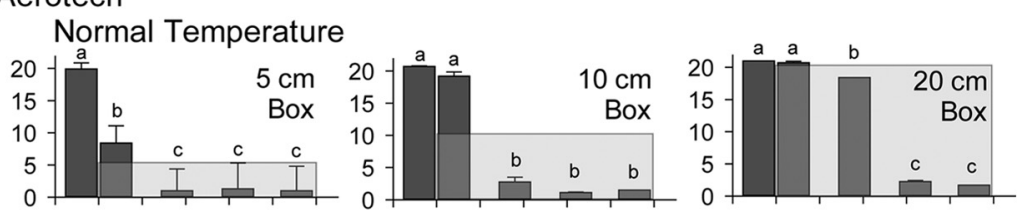

High Temperature
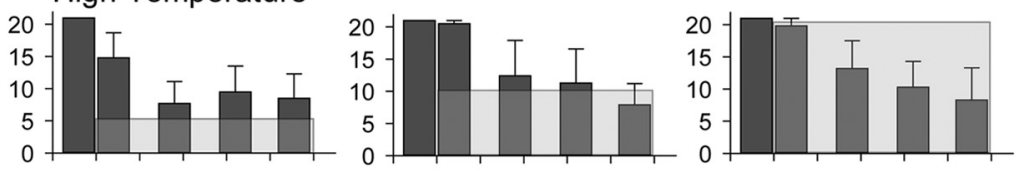

Pyrocide
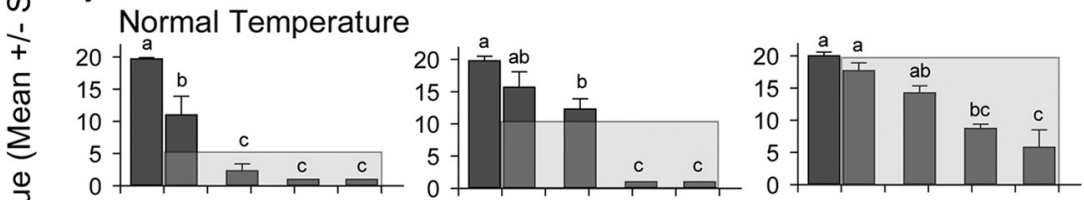

\section{High Temperature}
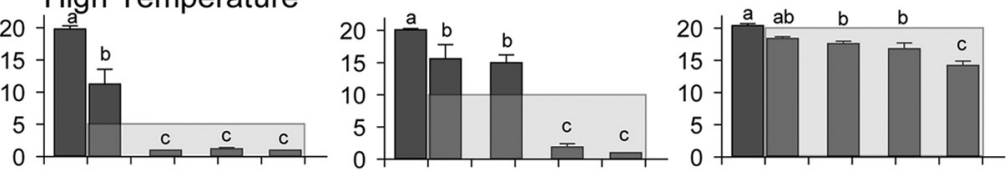

\section{Vap20}

\section{Normal Temperature}
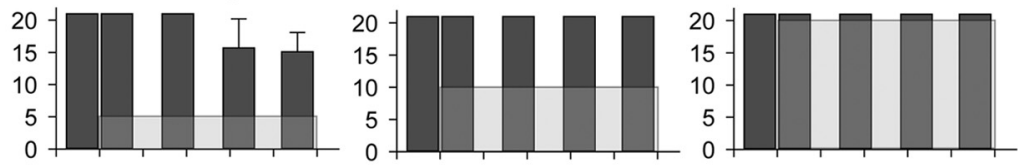

High Temperature
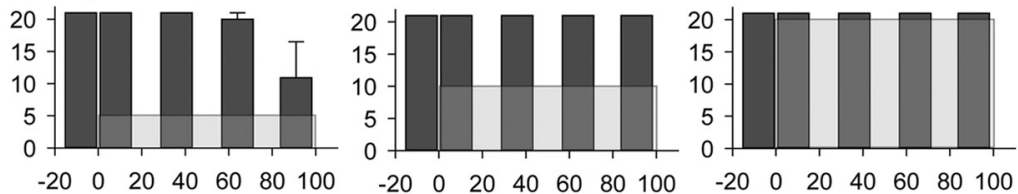

\section{Distance from Opening in Box $(\mathrm{cm})$}

Fig. 5. Mean \pm SEM efficacy index value-range from lowest efficacy value of 1 up to highest efficacy value of 21 - for dishes containing five $T$. confusum placed under boxes $1 \mathrm{~m}$ in depth, $20 \mathrm{~cm}$ in width, and 5,10 , or $20 \mathrm{~cm}$ in height. Rows of five dishes were placed $8 \mathrm{~cm}$ in front of box opening, and 8,36,64, and $91 \mathrm{~cm}$ under the box, with the light gray boxes in the graphs illustrating the different box heights as well as the position of the dishes under the boxes. Separate graphs are shown for three aerosol insecticides (Aerotech, Pyrocide, and Vap20) applied at both normal and high temperatures. Only efficacy index values 2 -wk postexposure are shown, and bars within a graph with the same letter have means that are not significantly different from each other (ANOVA and Ryan-Einot-Gabriel-Welsch multiple range test). Graphs with no letter above bars were not significantly different based on ANOVA test.

\section{Discussion}

These experiments revealed some interesting and unexpected patterns in aerosol deposition that illustrate how variation in formulation, application method, physical landscape, and temperature can interact to create spatial pattern in efficacy within a facility. It is important to note that the experimental protocol used was designed to detect variation in deposition and not to measure the full impact of these different insecticides on pest populations, as it only evaluates impact on adults directly exposed to aerosol, does not allow insects to avoid treatment, and does not measure the impact of the IGR portion of two of the formulations, which could provide additional efficacy. Furthermore, the applicator was constrained to applying the aerosols from a single point to facilitate comparisons. Although single-position applications are not unusual for rooms of the size used in this study, 
coverage could have been improved by applicator moving more during the application. However, our results do show the utility of this approach for determining aerosol deposition pattern and identifying potential factors impacting dispersion and deposition.

Understanding spatial pattern of deposition is critical for assessing efficacy of aerosol applications, and all insecticide formulations exhibited, to a greater or lesser extent, spatial variation in efficacy. Aerosol droplet dispersion and deposition is a complex process that is influenced by many factors including particle size distribution, release velocity and direction, physical landscape, and air speed and turbulence (World Health Organization 2003). The Aerotech and Pyrocide aerosols exhibited the greatest spatial variation in efficacy and differed from each other in level of variation and response to temperature. There are a variety of factors that differ between these aerosols that might contribute to these differences: different formulations, application methods, concentrations of (AI), and droplet size distribution and release velocity. Greater variation in efficacy could result from less (AI) being applied with Aerotech than with Pyrocide. As illustrated with the Vap20 treatment, if overall efficacy is high the bioassay will not detect spatial variation in deposition. It could be that the Aerotech was producing efficacy in the range that could be more easily detected with the bioassay and as a result more visible in the contour maps. However, that some areas had higher efficacy with Aerotech than with Pyrocide suggests that this is not the primary factor generating variation in efficacy.

The Aerotech and Pyrocide application methods could produce differences in the distribution of droplet sizes, number of droplets, and the release velocity. These parameters have been shown to influence aerosol dispersion and deposition in other systems, but specific information is not available for the insecticides used in this study. During application the droplets are propelled into the room, and as terminal velocity is reached owing to friction in the air they settle out of the air. Larger droplets tend to travel further, but methods to produce larger droplets tend to produce a slower release velocity. Small droplets tend not to travel as far because their terminal velocity is lower than larger droplets, but application equipment tends to release them at a higher initial velocity. Smaller droplets will tend to settle more slowly than larger droplets. For example, to fall $10 \mathrm{~m}$ droplets $5 \mu \mathrm{m}$ in diameter take $3.7 \mathrm{~h}, 10-\mu \mathrm{m}$ droplets take $56 \mathrm{~min}$, and $20-\mu \mathrm{m}$ droplets take only $14 \mathrm{~min}$ (World Health Organization 2003). In outside applications against mosquitos, the distribution of droplets sizes changes as a function of distance from point of application, with larger droplets dispersing further downwind (Rathburn and Dukes 1989, Brown et al. 1993, Curtis and Beidler 1996).

Much of the research on aerosol applications is based on use as a space spray for flying or roosting insects on exposed surfaces, where treatment efficacy is increased by droplets remaining in the air for longer periods of time and direct impingement on insects needs to be considered. Droplet size impacts efficacy directly, as impingement on an insect is a function of droplet size (Himel 1969, Lofgren et al. 1973). The optimal droplet size for efficacy against mosquitoes was determined to be between 8 and $15 \mu \mathrm{m}$ (Mount et al. 1970b, Haile et al. 1982), but there is little published information on impact of droplet size, concentration, and exposure time on stored-product insects. During food facility aerosol treatments, only a small portion of the insects present are likely to be directly exposed during the brief period of time the aerosol droplets are in the air. Thus, another component of efficacy that needs to be evaluated is how droplets settle onto surfaces and the spatial patterns in efficacy that result from insect encounters with these surfaces posttreatment. It is therefore important to take a fresh look at the relationship between droplet size and efficacy in relation to food facility applications, as the goal is not only to provide efficacy against insects out and active, but to also provide good coverage of the surfaces to maximize efficacy post treatment as well. Another factor to consider is the interaction between settling droplets and food residues and other materials on surfaces that can absorb the insecticide or impede the direct exposure of insects. Our bioassay approach is focused primarily on measuring variation in the direct efficacy of exposed insects, although there may have also been some residual activity on the treated flour and dish.

The Aerotech formulation is described as producing smaller droplet sizes than standard aerosol applicators for a broader distribution of droplets. For one treatment with this insecticide, as part of a pilot test, droplets were measured at one location on the fourth floor using an Aerodynamic Particle Size system (APS; TSI Inc., Shoreview, MN). After initial aerosol release, there was a peak in Aerotech formulation concentration of over $1,000 \mathrm{mg} / \mathrm{m}^{3}$ with droplet sizes centered around $20 \mu \mathrm{m}$ (the maximum droplet size measureable with the APS system). In the period 4-10 min after application, droplets were primarily in the 10-12 $\mu \mathrm{m}$ range $\left(100-200 \mathrm{mg} / \mathrm{m}^{3}\right)$, and after $\approx 30 \mathrm{~min}$ the concentration was $10-60 \mathrm{mg} / \mathrm{m}^{3}$ and the droplet sizes were in the 3-4 $\mu \mathrm{m}$ range. These measurements were taken in the center of the room near the application point, and this pattern will likely be different in other locations within the room. Results do suggest that the droplets that are likely the most efficacious particle size had settled out relatively quickly and that the potential for shorter exposure periods being equally effective should be evaluated. For the Pyrocide applications, the Fogmaster model 7401 Microjet Fogger was used at the maximum flow rate. According to the label, the predicted droplet size should have been around $30 \mu \mathrm{m}$ at this flow rate, although in general oil-based carriers tend to produce smaller droplets than water-based carriers (Hoffmann et al. 2007), so the droplet sizes were perhaps smaller than this estimate. This range of particle sizes is still presumably larger than those produced during the Aerotech application. Release velocity of these larger Pyrocide droplets is also presumably lower than that of the 
droplets coming from the Aerotech compressed gas cylinder. These differences between the two aerosols might have contributed to differences in spatial pattern of efficacy-small droplets not traveling as far after release, even though released at faster initial velocity. Further evaluation of droplet concentration and size at different locations and times after release is needed to address this question.

Vap20 was also applied using a compressed $\mathrm{CO}_{2}$ gas application system like the Aerotech aerosol, which suggests that the droplet sizes should be similarly small. However, Vap20 is very different from the first two insecticides, as the active ingredient, the organophosphate dichlorvos, has a high vapor pressure and readily volatilizes at normal room temperatures. Dichlorvos vapor is highly toxic to insects and has been demonstrated to be an effective space treatment when applied as a vapor (Mattson et al. 1955, Gillenwater et al. 1971, Harein et al. 1971). Because this insecticide is toxic in the vapor phase, it is difficult to relate spatial pattern in efficacy with distribution of droplets and droplet size.

Some locations, such as in the farthest corner in the L-shaped room, were anticipated to have reduced efficacy owing to distance from release point. Jenson et al. (2010b) has previously shown that pyrethrins and IGR aerosol application efficacy against Plodia interpunctella (Hübner) (Lepidoptera: Pyralidae) eggs decreased (i.e., increased survival to adulthood from egg stage) with distance from a ceiling-mounted aerosol dispenser. Features within the interior of the room such as equipment and structural pillars, which we anticipated might impact aerosol deposition, did not in most cases have lower efficacy, and coverage in the interior of the room was relatively consistent. Other areas with lower efficacy were not initially predicted. Walls, especially in the opposite direction from which the aerosol spray was released, and the corners along the outer perimeter of the room were areas that tended to have lower efficacy. These findings suggest that under still air conditions, there can be limited drift of particles back behind the direction of aerosol release. The combination of smaller droplets and higher initial release velocity with Aerotech application might explain why this wall and corner effect was stronger with this application. That these areas of lower efficacy tended to be associated with walls and corners, suggests that there may be either increased impingement on the walls resulting in fewer aerosol droplets settling to the floor or that dispersal of droplets into these areas is impeded, but further research is needed in this area. It is possible that increasing the movement of air using fans during the aerosol treatment might help improve the dispersal into these areas, although this tactic might also create new areas with low efficacy. Because stored-product insects often roost on walls and walk following walls (Campbell and Hagstrum 2002), improving efficacy in these areas could be critical for increasing overall efficacy.

Obstructions can greatly limit the efficacy of aerosol insecticides by preventing droplet and changing droplet size distributions. In outside environments, factors such as tree canopy and buildings have been shown to reduce aerosol penetration (Mount et al. 1970a; Taylor et al. 1975; Perich et al. 1992, 2000). However, information on how specific physical features inside buildings impact aerosol insecticide dispersal is limited. Our experiment evaluating aerosol dispersal under different height boxes clearly demonstrates the impact that horizontal obstructions can have on aerosol deposition. Use of the boxes rather than just placing the dishes in different obstructed areas within the mill provides a standardized approach that better enables predictions to be made about where inadequate dosages might be deposited. Not surprisingly the smaller the gap the less dispersal under the horizontal barrier occurred. Gaps of the smallest height tested correspond to gaps that might be found under pallets, while the taller gaps correspond to those that can be found under some milling equipment. Using the information provided by our study, the gap height and depth of a specific feature within a facility could be measured and the distance high efficacy is predicted to be maintained determined. This information could then be used to guide where supplemental treatments might be needed: for example, directing aerosol spray into these specific areas, placement of fans to direct air containing droplets into the obstructed areas, supplemental applications of residual insecticides, sanitation activities.

When evaluating the spatial pattern in efficacy within the mill, equipment and structural features present inside appeared to have only a limited impact in the spatial pattern of efficacy. This is consistent with the finding of Jenson et al. (2010b) that found no difference in P. interpunctella development from egg to adulthood after exposure to pyrethrins and IGR aerosol application in either unobstructed or concealed locations. One reason for the lack of a clear impact of physical features in our study may have been that this is a newer mill with modern equipment that is mounted higher off the ground to facilitate cleaning, which resulted in few areas with small gap heights. Dishes were also not placed far under these pieces of equipment. Based on the box data, there may have been adequate drift under these types of horizontal obstacles to result in obstructed, adjacent, and open locations not differing in efficacy or if differences did occur, why they were not large. Where differences occurred, the locations that were covered and adjacent to vertical surfaces had similar efficacy levels. This suggests that vertical surface affects on aerosol dispersal may have been more of a factor than the horizontal coverage reducing dispersal. In older mills with equipment mounted closer to the ground, in rooms with a greater density of equipment, and in warehouses with pallets and low shelving, the effects of obstructions are likely to be even greater, potentially creating larger zones of lower efficacy.

Temperature has been demonstrated to impact the efficacy of pyrethrins, with greater efficacy at cooler temperatures (Blum and Kearns 1956). However, Kharel (2013) did not find a significant impact on the efficacy of a synergized pyrethrins aerosol at temper- 
atures between 22 and $32^{\circ} \mathrm{C}$. In our study, there were greater efficacy index values 24 -h postexposure at $40^{\circ} \mathrm{C}$ target temperature than at the $27^{\circ} \mathrm{C}$ target temperature. However, after 2 wk the Aerotech aerosol average efficacy index was similar between the two temperatures and for the Pyrocide aerosol efficacy was greater at the normal temperature than the high temperature after $2 \mathrm{wk}$. The insects were only exposed to different temperatures during exposure to the aerosol and aeration, and afterward all were held at the same $27^{\circ} \mathrm{C}$. So any impact of temperature directly on efficacy probably occurred only during the initial response to aerosol exposure.

Temperature may have also impacted the distribution and deposition of aerosol droplets, as temperature differentials can create convection currents that can transport smaller droplets away from surfaces. Although the airflow patterns within the mill during the two temperature treatments are unknown, it is possible that differences in air flow patterns could have occurred between the two temperatures. For example, the walls may have been warmer than the air inside the room once the heating system was turned off, and this could cause the cooler air coming into contact with the wall to rise. Rising air along walls could reduce aerosol deposition on floors adjacent to walls, which could contribute to the reduced efficacy observed in these locations. Smaller droplets are more likely to be impacted by this air movement, which might contribute to differences in spatial pattern of efficacy between the two pyrethrins evaluated. For example, with a $3 \mathrm{mph}$ wind $5-\mu \mathrm{m}$ droplets can travel a lateral distance of $4,828 \mathrm{~m}$ when falling $3 \mathrm{~m}$, while $20-\mu \mathrm{m}$ droplets travel only $335 \mathrm{~m}$ (Potts 1946, Akesson and Yates 1964). Given that this study reveals some interesting temperature effects on aerosol efficacy distribution, further research on temperature and air flow patterns inside structures during treatment and how temperature might be manipulated to increase efficacy are warranted.

The efficacy index developed helped to reduce the complexity of analyzing several different response variables generated by exposure to pyrethrin and pyrethroid insecticides. This type of bioassay approach has considerable potential for the evaluation of aerosol efficacy in locations where insects can be introduced; a similar approach using dishes into which insects are added after exposure could also be used. However, the relationship between this efficacy index and droplet deposition remains to be determined. The use of dye cards to measure droplet deposition is not accurate with the small sized droplets produced during aerosol application. The use of equipment such as the APS unit described above offers the potential to accurately determine droplet size and concentration, but cannot practically be used in more than a limited number of locations during a treatment. The methodology and results presented here provide new and novel information regarding spatial patterns of efficacy in aerosol applications within food facilities and opens up new areas of research that might improve the effectiveness of aerosol insecticides in management programs for the food industry.

\section{Acknowledgments}

We greatly appreciate and thank Rich Hammel, Brian Barnett, Kabita Kharel, Karrie Buckman, Laura Starkus, and Konner Cool for their technical assistance, Industrial Fumigant Company, especially Chelle Hartzer and Bill Craig, for performing the aerosol treatments, and Gerald Ducatte from MRIGlobal for performing the aerosol droplet size measurements. This research was partially funded by the U.S. Department of Agriculture, National Institute of Food and Agriculture (NIFA) Methyl Bromide Transitions program (grant 2010-51102-21660). This manuscript is contribution no. 14-091-J from the Kansas Agricultural Experiment Station, Kansas State University, Manhattan, KS.

\section{References Cited}

Akesson, N. B., and W. E. Yates. 1964. Problems relating to application of agricultural chemicals and resulting drift residue. Annu. Rev. Entomol. 9: 285-318.

Arthur, F. H. 1988. Evaluation of an aerosol formulation containing cyfluthrin against three species of stored product insects. J. Entomol. Sci. 23: 257-263.

Arthur, F. H. 1993. Evaluation of prallethrin aerosol to control stored product insect pests. J. Stored Prod. Res. 29: 253-257.

Arthur, F. H. 2008. Aerosol distribution and efficacy in a commercial food warehouse. Insect Sci. 15: 133-140.

Arthur, F. H. 2010. Residual efficacy of aerosols to control Tribolium castaneum and Tribolium confusum, pp. 789792. In M. O. Carvalho, P. G. Fields, C. S. Adler, F. H. Arthur, C. G. Athanassiou, J. F. Campbell, F. FleuratLessard, P. W. Flinn, R. J. Hodges, A. A. Isikber, et al. (eds.), Proceedings of the 10th International Working Conference on Stored Product Protection, 27 June to 2 July 2010, Estoril, Portugal. Julius Kühn-Institut, Berlin, Germany.

Arthur, F. H. 2012. Aerosols and contact insecticides as alternatives to methyl bromide in flour mills, food production facilities, and food warehouses. J. Pest Sci. 85: 323329.

Arthur, F. H., and J. F. Campbell. 2008. Distribution and efficacy of pyrethrin aerosol to control Tribolium confusum (Coleoptera: Tenebrionidae) in food storage facilities. J. Stored Prod. Res. 44: 58-64.

Arthur, F. H., and H. B. Gillenwater. 1990. Evaluation of esfenvalerate aerosol for control of stored product insect pests. J. Entomol. Sci. 25: 261-267.

Arthur, F. H., J. F. Campbell, E. A. Fontenot, and M. E. Toews. 2013. Assessing effects of esfenvalerate aerosol on resident populations of Tribolium castaneum (Herbst), the red flour beetle, through direct and indirect sampling. J. Stored Prod. Res. 53: 1-6.

Blum, M. S., and C. W. Kearns. 1956. Temperature and the action of pyrethrum in the American cockroach. J. Econ. Entomol. 49: 862-865.

Boina, D. R., and B. Subramanyam. 2012. Insect management with aerosols in food processing facilities, pp. 195212. In F. Perveen (ed.), Insecticides: advances in integrated pest management. InTech, New York, USA. (http://www.intechopen.com).

Brown, J. R., V. Chew, and R. O. Melson. 1993. Malathion aerosol cloud behavior in a coastal plains pine flat woods. J. Am. Mosq. Control Assoc. 9: 91-93. 
Campbell, J. F., and D. W. Hagstrum. 2002. Patch exploitation by Tribolium castaneum: movement patterns, distribution, and oviposition. J. Stored Prod. Res. 38: 55-68.

Curtis, G. A., and E. J. Beidler. 1996. Influence of ground ULV droplet spectra on adulticide efficacy for Aedes taeniorhynchus. J. Am. Mosq. Control Assoc. 12: 368-371.

Gillenwater, H. B., P. K. Harein, E. W. Loy, Jr., J. F. Thompson, H. Laudani, and G. Eason. 1971. Dichlorvos applied as a vapor in a warehouse containing packaged foods. J. Stored Prod. Res. 7: 45-56.

Haile, D. G., G. A. Mount, and N. W. Pierce. 1982. Effect of droplet size of malathion aerosols on kill of caged adult mosquitoes. Mosq. News. 42: 576-583.

Harein, P. K., H. B. Gillenwater, and G. Eason. 1971. Dichlorvos space treatment for protection of packaged flour against insect infestation. J. Stored Prod. Res. 7: 57-62.

Himel, C. M. 1969. The optimum size for insecticide spray droplets. J. Econ. Entomol. 62: 919-926.

Hoffmann, W. C., T. W. Walker, V. L. Smith, D. E. Martin, and B. K. Fritz. 2007. Droplet-size characterization of handheld atomization equipment typically used in vector control. J. Am. Mosq. Control Assoc. 23: 315-320.

Hoffmann, W. C., B. K. Fritz, M. Farooq, and M. F. Cooperband. 2008. Effects of wind speed on aerosol spray penetration of mosquito bioassay cages. J. Am. Mosq. Control Assoc. 24: 419-426.

Jenson, E. A., F. H. Arthur, and J. R. Nechols. 2010a. Efficacy of an esfenvalerate plus methoprene aerosol for the control of eggs and fifth instars of Plodia interpunctella (Hübner) (Lepidoptera: Pyralidae). Insect Sci. 17: 21-28.

Jenson, E. A., F. H. Arthur, and J. R. Nechols. 2010b. Methoprene and synergized pyrethrins as aerosol treatments to control Plodia interpunctella (Hübner), the Indian meal moth (Lepidoptera: Pyralidae). J. Stored Prod. Res. 46: 103-110.

Kharel, K. 2013. Evaluation of pyrethrin aerosol insecticide as an alternative to methyl bromide for pest control in flour mills. M.S. thesis, Kansas State University, Manhattan.

Kharel, K., F. H. Arthur, K. Y. Zhu, J. F. Campbell, and B. H. Subramanyam. 2013. Susceptibility of different life stages of Tribolium confusum to pyrethrin aerosol: effects of flour source on insecticidal efficacy. J. Stored Prod. Res. (in press)

Lehnert, M. P., R. M. Pereira, P. G. Koehler, W. Walker, and M. S. Lehnert. 2011. Control of Cimex lecturlarius using heat combined with dichlorovos resin strips. Med. Vet. Entomol. 25: 460-464.

Lofgren, C. S., D. W. Anthony, and G. A. Mount. 1973. Size of aerosol droplets impinging on mosquitoes as determined with a scanning electron microscope. J. Econ. Entomol. 66: 1085-1088.

Mattson, A. M., J. T. Spillane, and G. W. Pearce. 1955. Dimethyl 2,2-dichlorvinyl phosphate (DDVP), an organic phosphorus compound highly toxic to insects. J. Agric. Food Chem. 3: 319-321.

Mount, G. A., C. T. Adams, W. G. Pearson, C. S. Lofgren, and D. E. Weidhass. 1970a. Ultralow volume aerial sprays of malathion and fenthion for anopheline mosquito control in Panama Canal Zone jungle. Mosq. News 30: 604-610.

Mount, G. A., N. W. Pierce, C. S. Lofgren, and J. B. Gahan. 1970b. A new ultra-low volume cold aerosol nozzle for dispersal of insecticides against adult mosquitoes. Mosq. News 30: 56-59.

Peckman, P. S., and F. H. Arthur. 2005. Insecticide space treatments in food plants, pp. 175-182. In J. W. Heaps (ed.), Insect management for food storage and processing, 2nd ed. AACC International, St. Paul, MN.

Perich, M. J., B. L. Bunner, M. A. Tidwell, D. C. Williams, C. D. Mara, and T. Carvalhe. 1992. Penetration of ultralow volume applied insecticide into dwellings for dengue vector control. J. Am. Mosq. Control Assoc. 8: 137-142.

Perich, M. J., G. Davila, A. Turner, A. Garcia, and M. Nelson. 2000. Behavior of resting Aedes aegypti (Culicidae: Diptera) and its relation to ultra-low volume adulticide efficacy in Panama City, Panama. J. Med. Entomol. 37: 541-546.

Potts, S. F. 1946. Particle size of insecticides and its relation to application, distribution and deposits. J. Econ. Entomol. 39: 716-720.

Rathburn, C. B., Jr., and J. C. Dukes. 1989. A comparison of the mortality of caged adult mosquitoes to the size, number and volume of ULV spray droplet sampled in an open and a vegetated area. J. Am. Mosq. Control Assoc. 5:173175.

Schleier, J. J., and R.K.D. Peterson. 2011. Pyrethrins and pyrethroid insecticides. In Ó. López and J. FernándezBolaños (eds.), Green trends in insect control, RSC Publishing, Cambridge, United Kingdom.

Schneider, C. A., W. S. Rasband, and K. W. Eliceiri. 2012. NIH Image to ImageJ: 25 years of image analysis. Nat. Methods 9: 671-675.

Strong, R. G., and D. E. Sbur. 1964. Influence of grain moisture and storage temperature on the effectiveness of five insecticides as grain protectants. J. Econ. Entomol. 57: $44-47$.

Subramanyam, B. H., D. R. Boina, and F. H. Arthur. 2014. Exposure location and bioassay method on efficacy of dichlorvos applied as an aerosol against Tribolium confusum adults and Tribolium castaneum pupae in a flour mill. J. Stored Prod. Res. (in press)

Sutton, A. E., F. H. Arthur, K. Y. Zhu, J. F. Campbell, and L. Murray. 2011. Residual efficacy of pyrethrin + methoprene aerosol against larvae of Tribolium castaneum and Tribolium confusum (Coleoptera: Tenebrionidae). J. Stored Prod. Res. 47: 399-406.

Taylor, R. T., M. Solis, D. B. Weathers, and J. W. Taylor. 1975. A prospective study of the effects of ultralow volume (ULV) aerial application of malathion on epidemic Plasmodium falciparum malaria. II. Entomological and operational aspects. Am. J. Trop. Med. Hyg. 24: 188-192.

Toews, M. E., F. H. Arthur, and J. F. Campbell. 2010. The presence of flour affects the efficacy of aerosolized insecticides used to treat the red flour beetle, Tribolium castaneum. J. Insect Sci. 10: 196.

Tucker, A. M., J. F. Campbell, F. H. Arthur, and K. Y. Zhu. 2014. Horizontal transfer of methoprene by Tribolium castaneum (Herbst) and T. confusum Jacquelin du Val. J. Stored Prod. Res. (in press)

World Health Organization. 2003. Space spray application of insecticides for vector and public health pest control. WHO/CDS/WHOPES/GCDPP/2003.5, Geneva, Switzerland.

Received 25 September 2013; accepted 26 November 2013. 